\title{
FROM CAD TO DIGITAL MODELING: THE NECESSARY HYBRIDIZATION OF PROCESSES
}

\author{
Giovanna A. Massari $^{\text {a * }}$, Fabio Bernardi $^{\text {a }}$, Alberto Cristofolini ${ }^{\text {a }}$ \\ ${ }^{a}$ Engineering Faculty, University of Trento, Via Mesiano, 77 - I-38123 Trento \\ tel. +39046128.2644 / 2615 - fax +390461 282672 \\ \{Giovanna.Massari, Fabio.Bernardi\}@ing.unitn.it; alberto@cristofolini.191.it
}

KEY WORDS: 3D modelling, Building, Computer simulation, Education, Interoperability, Object reconstruction

\begin{abstract}
:
The essay deals with the themes of digital representation of architecture starting from several years of teaching activity which is growing within the course of Automatic Design of the degree course in Engineering/Architecture in the University of Trento. With the development of CAD systems, architectural representation lies less in the tracking of a simple graph and drawn deeper into a series of acts of building a complex digital model, which can be used as a data base on which to report all the stages of project and interpretation work, and from which to derive final drawings and documents.

The advent of digital technology has led to increasing difficulty in finding explicit connections between one type of operation and the subsequent outcome; thereby increasing need for guidelines, the need to understand in order to precede the changes, the desire not to be overwhelmed by uncontrollable influences brought by technological hardware and software systems to use only in accordance with the principle of maximum productivity. Formation occupies a crucial role because has the ability to direct the profession toward a thoughtful and selective use of specific applications; teaching must build logical routes in the fluid world of info-graphics and the only way to do so is to describe its contours through method indications: this will consist in understanding, studying and divulging what in its mobility does not change, as procedural issues, rather than what is transitory in its fixity, as manual questions.
\end{abstract}

\section{RÉSUMÉ:}

Cet essai a pour objet la question de la représentation numérique de l’architecture, en partant des enseignements donnés dans le cours de Dessin Automatique, à l'intérieur du diplôme en Ingénierie / Architecture de l'Université de Trento. Grâce au développement des systèmes CAD, la représentation de l'architecture consiste toujours moins en la réalisation d'un simple dessin, mais plutôt en la construction d'un modèle numérique très élaboré; ce modèle-ci peut être utilisé comme base des données où rapporter toutes les différentes phases du projet et de l’interprétation, et d'où tirer les dessins et les documents définitifs.

L'utilisation des technologies numériques a entraîné beaucoup de difficultés dans le repérage de relations directes entre un certain genre d'opération et le résultat que celle-ci produit; on a, donc, de plus en plus besoin de s'orienter, de comprendre pour essayer de devancer les changements, de ne pas tomber sous les incontrôlables conditionnements technologiques apportés par les systèmes hardware et software - systèmes qu'il faut utiliser selon le principe du maximum de productivité. La formation est très importante; elle peut pousser la profession vers l'emploi pondéré et sélectif des logiciels d'application. Il faut cependant que l'enseignement bâtisse des itinéraires logiques dans le milieu de l'infographique, et on peut y réussir seulement à partir des indications fournies par la méthode. C'est-à-dire qu'il faut comprendre, étudier et diffuser tout ce qui dans sa mobilité ne change pas - les aspects liés à la pratique -, à la place de ce qui est fixe mais transitoire - les aspects livresques.

\section{INTRODUCTION}

The reflections that follow relate to architecture as a set of manmade forms necessary to make habitable a natural context, and in particular its representation and the ways to develop, communicate and manage both the design of new constructions and the analysis of the existent ones.

Digital technologies have radically changed the procedures, methods and tools of representation and therefore, in the contemporary world, the approach to the problems of processing and knowledge of the spaces in which we live, is different.

The computerized representation of such procedures seem destined to play a central role both in production and coordination of the project and the investigation and preservation of historical artefacts; they provide a wide transmissibility of the achieved results, moreover the transition from specialistic knowledge to widespread communication, by the means of graphic and multimedia elaborates which are a quoted and essential tool in different processes, including otherwise intended ones.

With the development of CAD systems, architectural representation lies less in the simple tracking of a paper chart, and increasingly in a number of constructive acts of a complex digital model, defined on the basis of the formal, structural and functional components. One of the potential highlights of the info-graphic 3D building, town or territorial model, compared with the traditional graph model, is the possibility of using interoperable software technologies: an interoperable representative model is accessible by informatics instruments of

\footnotetext{
* Corresponding author.
} 
different nature and can be shared by several operators, so it can be used as a data base on which to report all phases of the project work and interpretation, and from which to derive the final drawings and documents.

This is the meaning of "required process hybridization" spoken of in the title, with respect to which training has a crucial role because it has the ability to direct the profession toward a thoughtful and selective use of computerized applications, would help the recovery of a strong link between training and profession, and to overcome the crisis presently faced by both realities.

\section{THE WORLD OF INFO-GRAPHICS}

The computerized representation is experiencing a period of frenetic changes that seem to lack a clear direction and, in contrast, seem marked by the proliferation of accidental events and planned alternatives; in addition to this, it is widely believed that the advent of digital technologies has resulted in an increasing difficulty in finding explicit connections between a type of operation and the consequent result: the cause resides, also in architecture and its representation, in the radical gap between those who produce and maintain the tools of everyday work and the users, including professionals involved in human landscapes and that govern transformations.

Therefore the need to be oriented, to understand and precede the changes, the desire not to be overwhelmed by uncontrollable influences brought by technological hardware and software systems to use in accordance with the principle of maximum productivity, increases. Firms, in fact, tend to put on market even more all-encompassing computer applications, which aspire to be passepartout able to open and close an entire analytic process and planning, but that not always are interpreted in a way relevant to the real needs of architecture. On the other hand, architects and engineers are inclined to adapt their development, administration and construction of the product work, to the instrumental availability at the moment, believing to be able to realize whatever a software allows to do and, more importantly, to realize it better with the use of "packages" useful for all stages and therefore often more expensive.

In reality, rarely individual applications on the market are able to answer fully and address satisfactorily the various needs of the designer and info-graphic designer, a professional, the latter, which has now forcefully entered the world of multimedia productions. This confirms the fundamental importance that the definition of the succession and concatenation operations required to complete a specific project or investigative process, as a teaching profession, assumes. In order not to sacrifice the illusion of being able to defend freedom of thought, it will be necessary to create routes in the fluid world of info-graphics the only logical way to do this is to describe the contours through indications of method, still with the inability to identify and recognize the focal point; it will be necessary to understand, study and divulge what in its mobility does not change, that is to say procedural issues, rather than what is transitory in its fixity, which are manual matters.
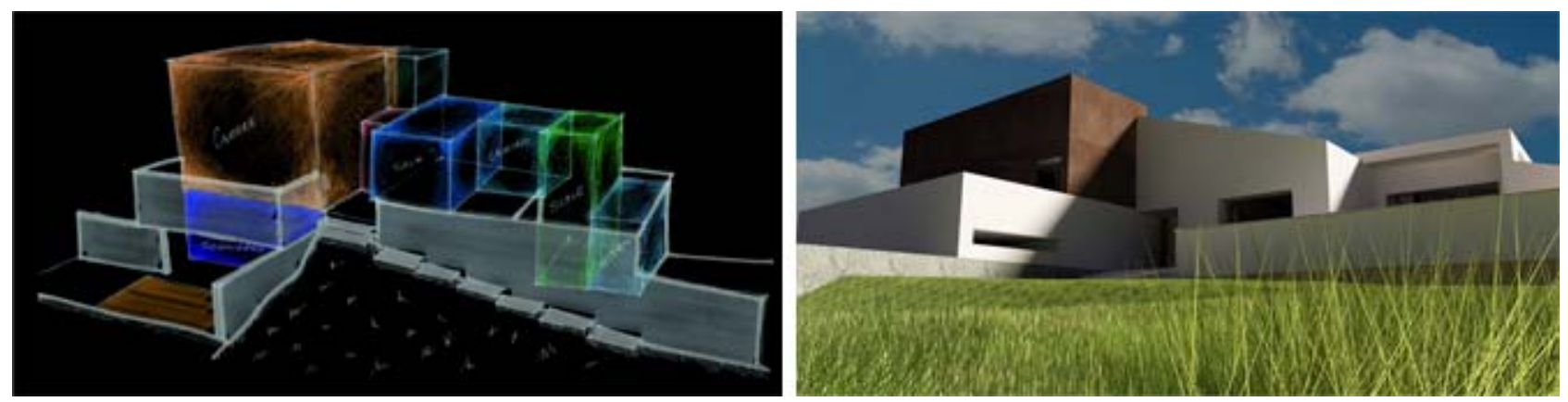

Figure 1. "C" House (arch. Vittorio Longheu): from the project to the virtual representation of the 3D model (author: Michele Brunelli)
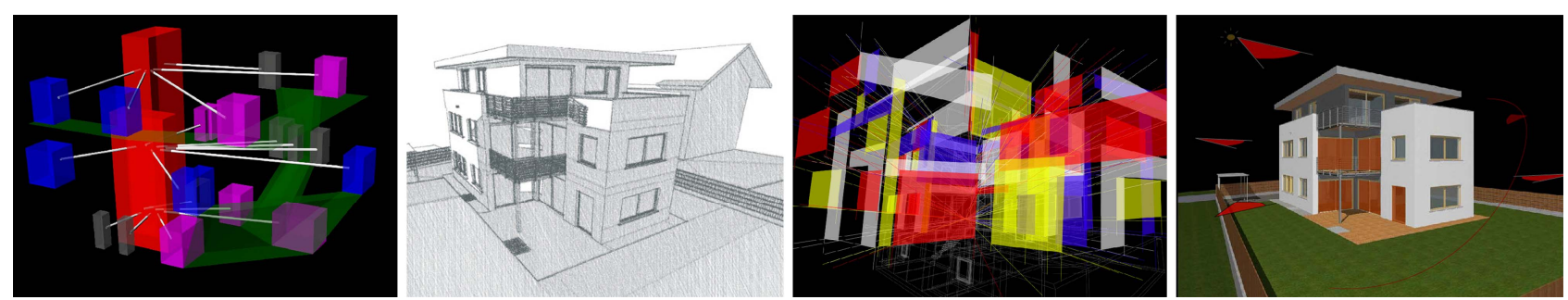

Figure 2. Niederkofler Haus (Plankensteiner \& Steger Architects): from the performance schedule to the construction of the digital 3D model (authors: Giovanni Beggio, Alberto Bragagnolo, Giacomo Longo, Roberto Tubaro)

\section{MODELS FOR CONSTRUCTION AND COMMUNICATION}

The innovation of computer graphics tools in the service of architectural design has changed in the subsequent growth of the phases of design thought and in particular the link between idea and design, in traditional design is first a research tool, then it becomes an indispensable representation and communication of the project tool and, ultimately, construction of architecture. This sequence of project phases is now being reversed by the use of innovative digital tools that allow to bring the construction of architecture within the "heuristic circle" which is the basis of the inventive step: as the designer has available, in a virtual building site, at an early stage, a new tool to research and verify the idea to accompany the drawing. The construction of virtual architecture, using systems of 
parametric simulation follows the same rules codified in real building that, far from being in conflict with the design, tends to expand its boundaries. In this way, the 3D CADs establish new procedures to access information, because they allow to set up a real "integrated database" of design data shared between operators: the model is indeed able to relate the various features artefact of either related to geometrical, structural, material, technical, economic, administrative or programmatic aspects. The application of parametric design can plan an increasingly complex to manage and difficult to reproduce mechanism: just think about the issues of implant and sustainability as well as those of construction site work.

The training of specialists, however, can not overlook the role that image communication plays today in contemporary society: the only way of knowing the world around us and act on what now seems to reside in the synthetic images obtained from digital modelling, being them quality static photographic views or dynamic sequences with satisfying cinematic intent.

The control of modelling and rendering processes, by which are generated geometric and figurative modelling and all eidomatic representations therein contained, often requires the ability to handle tools and techniques born with other objectives, for example video games development It is so necessary to learn to contaminate software functions, to hybridize its fields of application, to choose different computer resources in respect to the different needs and on the basis of actual interoperability; precisely to the extent where many of the solutions offered by the market are based on fixed procedures, they may be less suited to the purposes for which they were designed and useful for others.
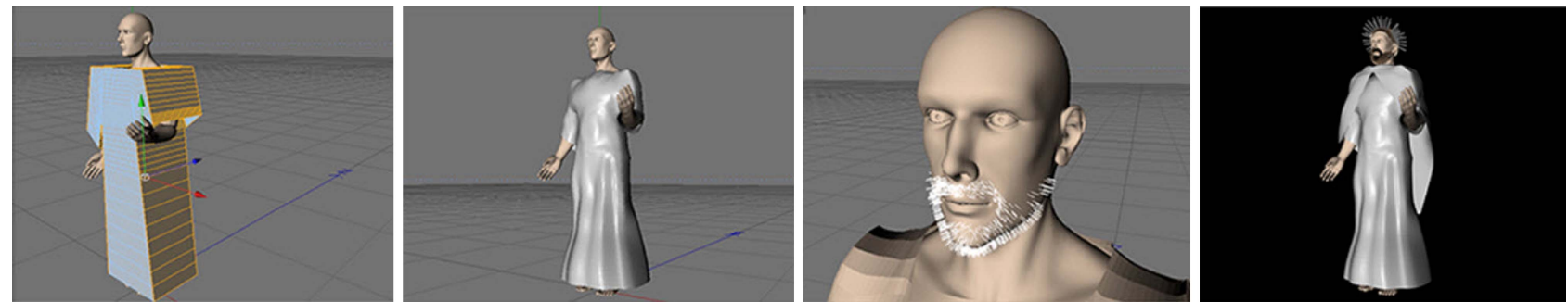

Figure 3. San Michele Chapel, San Romedio hermitage (TN): modelling and rendering process for the virtual simulation of sculptural elements (authors: Serena Christofides, Andrea Ghensi)
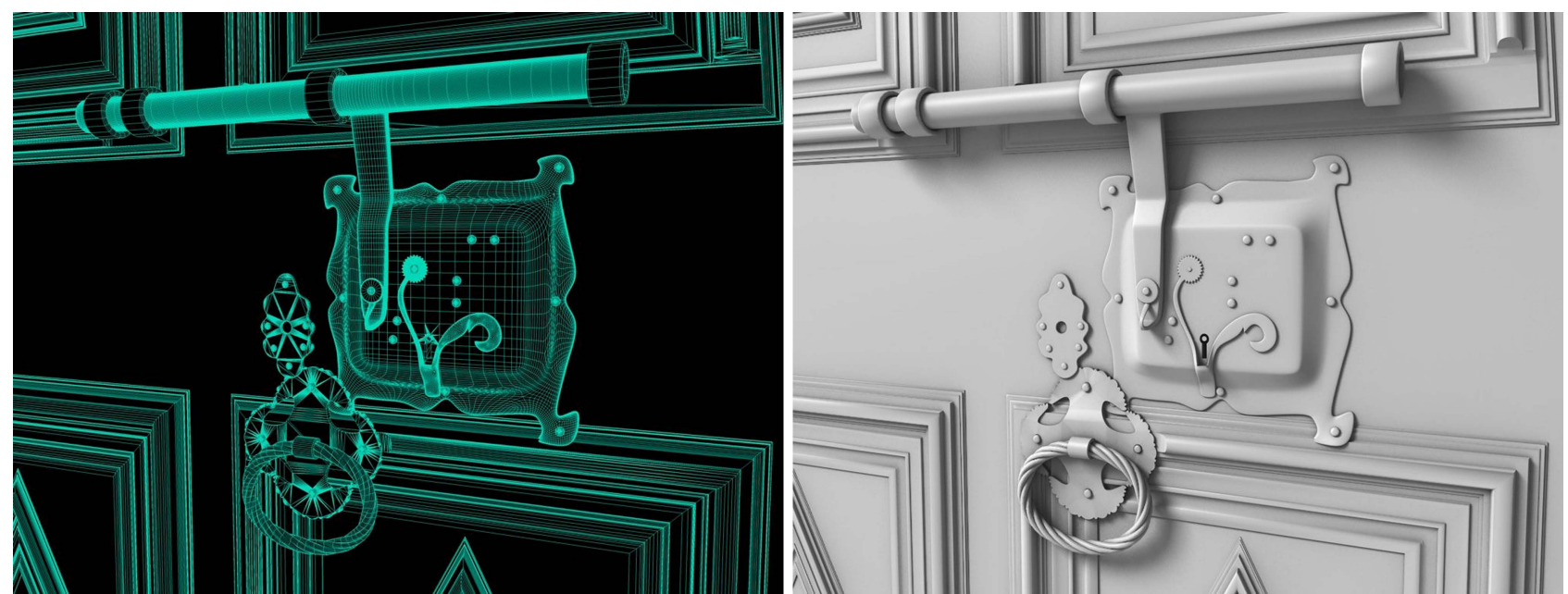

Figure 4. San Romedio Chapel, San Romedio hermitage (TN): modelling of constructive details for the representation of historical and artistic assets (authors: Stefano Longo, Lucia Pradel)

\section{A DIDACTIC EXPERIENCE: THEMES}

On these issues there is now a training activity aimed at establishing the stages of a hypothetical journey into the world of computer design and explaining the main processes of image construction used by computers, nonetheless the areas of operational possibilities of the boundaries today reachable and the developments to be expected in the future: an experience that, for this reasons wants to be at "low obsolescence" and that since some years ago is growing within the teaching of
Automatic Design of the degree course in Engineering / Architecture of the University of Trento.

The course aims to provide the necessary elements to use informatics tools to design by multimedia, culminating with the creation of a $3 \mathrm{D}$ model from which it is possible to obtain technical drawings and meaningful presentations by rendering and animation softwares. The objects chosen for practical exercises are different and therefore the subjects of study are variable. 

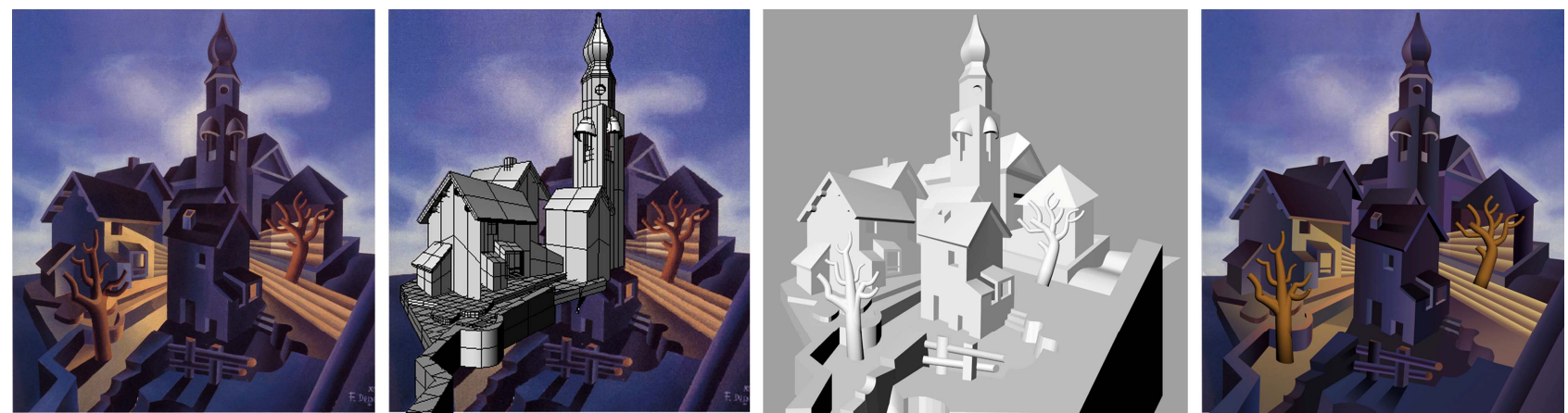

Figure 5. "Case alpestri in blu” (Fortunato Depero): from the picture to the digital model and its virtual image construction (author: Tiziana Bianchi)

A first opportunity for experimentation is given by the analysis of a painting and involves the reconstruction of a 3D "virtual scene" from a 2D image. In this case, the work follows specific stages: interpretation of drawn volumes, assignment of measures consistent with the geometrical model generated in $3 \mathrm{D}$, development of a model through notional allocation of material characteristics, application of textures, the study of colour, the choice of light sources and analysis of the shadows they produce; generation of static, dynamic and interactive synthesis images, that reproduce appropriately, the architectural space evoked in the analysed work.

A second issue concerns a contemporary designed architecture product, of small size and properly documented monographs, exhibition catalogs and magazines. The study is carried out investigating the various graphical models of the different project phases: the pre-figuration of the idea, that is the focus of the first formal elaboration of inspirational criteria through which the project takes shape and is measured contextualized; the concise and emblematic presentation of the project to customers, for a competition or a publication, based on the generation of a three-dimensional model of the building with digital techniques; self-celebration of the project, which aims to highlight the constants and deviations of creative processes and the factors that characterize syntactic and poetic work; the administration of the project by means of coded representations required by bureaucracy and control authorities in various fields; and finally, the practical implementation and information transmission to the construction company and the other operators that translate into physical reality the designs drawn by the architect.

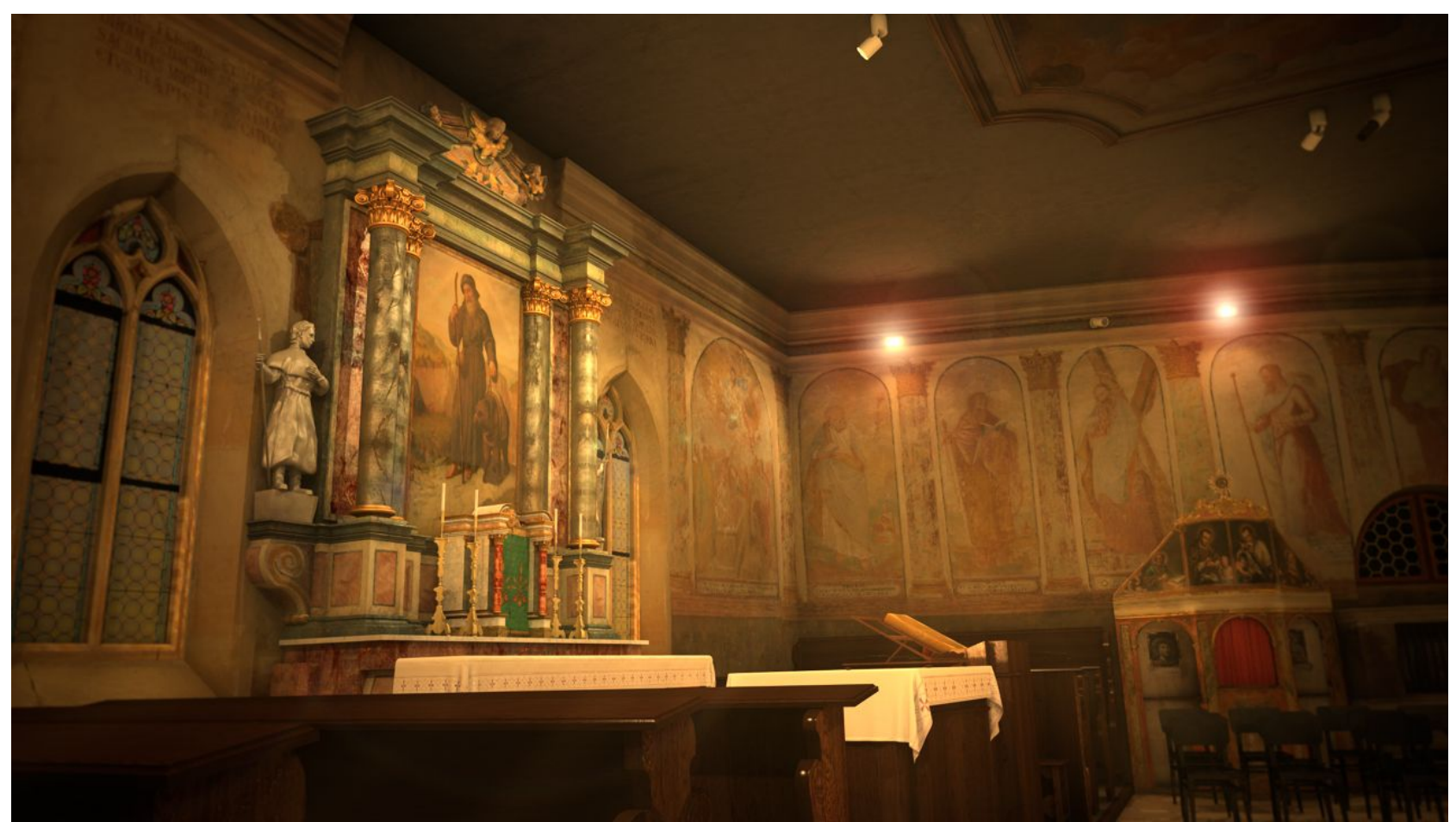

Figure 6. San Romedio Chapel, San Romedio hermitage (TN): digital photorealistic image exported from the 3D figurative model (authors: Stefano Longo, Lucia Pradel) 


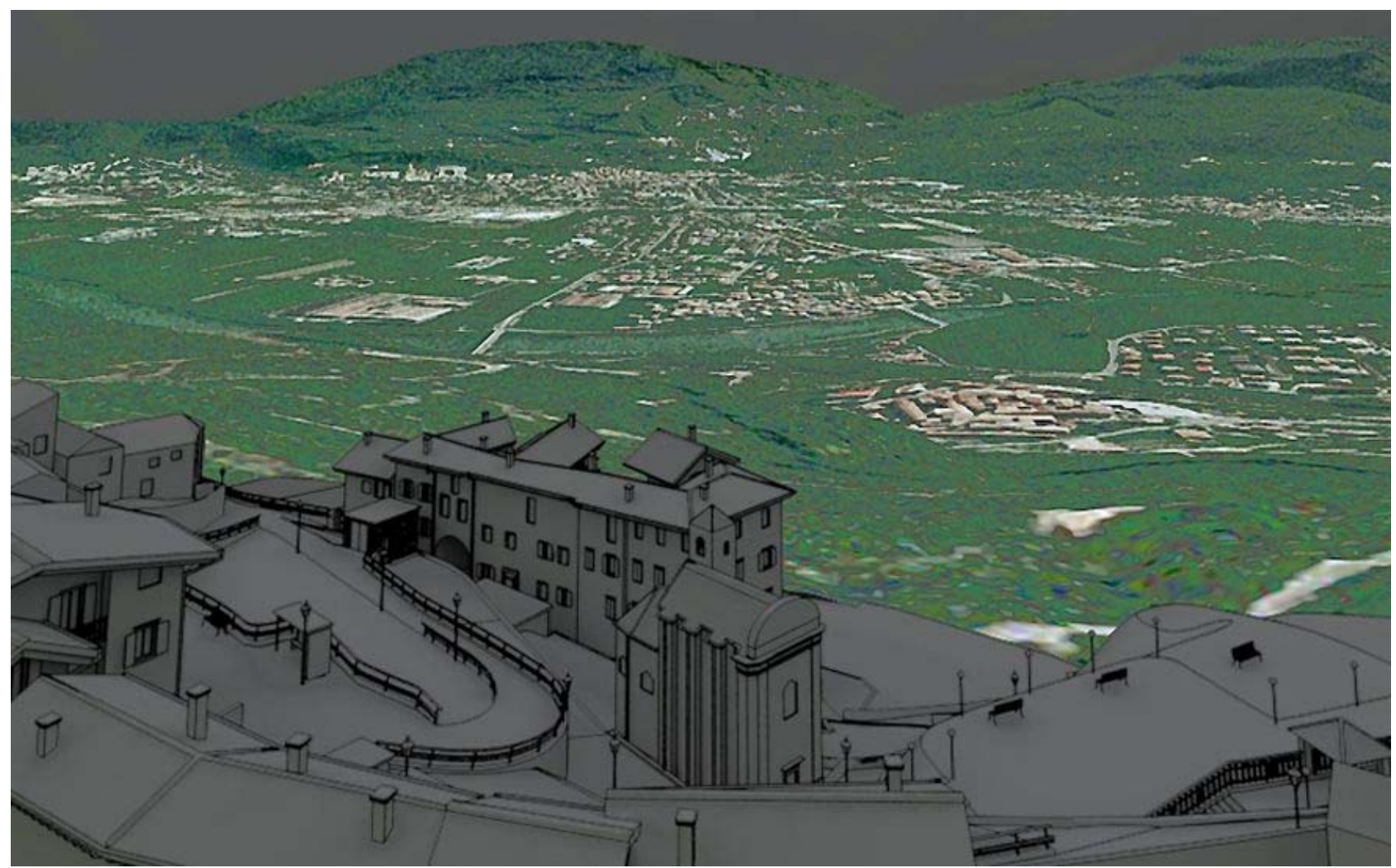

Figure 7. Folaso, hamlet of Isera (TN): 3D urban model visualization related to its territorial context (authors: Francesca Angileri, Jole Avi, Marta Cocco, Claudia Valente)

A third and perhaps more complex scope is focused on the reading and critical analysis of "how" an architectural site "is made", through the development of representative models that address the theme of "space" and "temporality" of the built constructions in multiple relations with the context; these infographic models are primarily directed to a deepened "description of present time", which is the correct representation of a physical reality, but often also deal with the "interpretation of present time", the "reconstruction of past" and the "forecast of future". The description of present time, referring to existing documentation and data collected through surveys, takes place with the geometric model of the building volume, soil's morphology, and figurative model at architectural scale that closely represents formal characteristics, materials and coloristic elements: some significant results at a technical level are achieved rebuilding statues and sculptural elements and in rendering vegetation.

By contrast, the interpretation of present includes heterogeneous themes: functional aspects, such as paths' dynamics and the relation between public and private spaces; the degradation of artefacts and pertinent evaluation of interventions; the perceptive characters related to the buildings' "external" sight and from "outside" vision; the non-projective and non-visual dimensions related to touch, hearing and smell; the site quality in changing environmental conditions. The reconstruction of the past rather aims at achieving delineated outcomes: virtual reconstruction of never realised design solutions and the comparison of different project ideas; the digital revival of demolished, in whole or in part, historic buildings or of the subsequent configurations of a manufacture product in its historical evolution. Finally, the forecast of future allows identification of the place's elements and characteristics to be taken as rules for design intervention and protection, and formulate alternatives for augmentation at architectural, urban and environmental scale.

\section{A DIDACTIC EXPERIENCE: PROCEDURES}

The amplification of the themes dealt with above relies on a series of lectures ranging from the procedures of creation of 3D models to the finalization of the methods by which the use of the models themselves and focus on the areas of representation and production of images, the achievement of traditional drawings and, finally, the field of multimedia and telematic communications.

Geometric 3D modelling offers different solutions depending on nature of the work and the object of study: in any case, like any other virtual implementation, involves the problem of loss of information. Therefore, modelling wireframe techniques, for surfaces, NURBS or solid geometry must be assessed in relation to some intrinsic properties: the ability of the model of corresponding to the shape that represents, the attitude of the model of supporting information related to the object, the suitability of instruments of representation in managing complex shapes and, ultimately, the resources needed to run the application. The family of CAD applications and / or solid modelling allows to build the deck of a three-dimensional object: to 3D modellers is usually entrusted the development of forms not reconfigurable to box-schemes, while vector softwares are used to generate basic geometric models and as "collector tools" that facilitate both the exchange of files and the printing of final papers. 


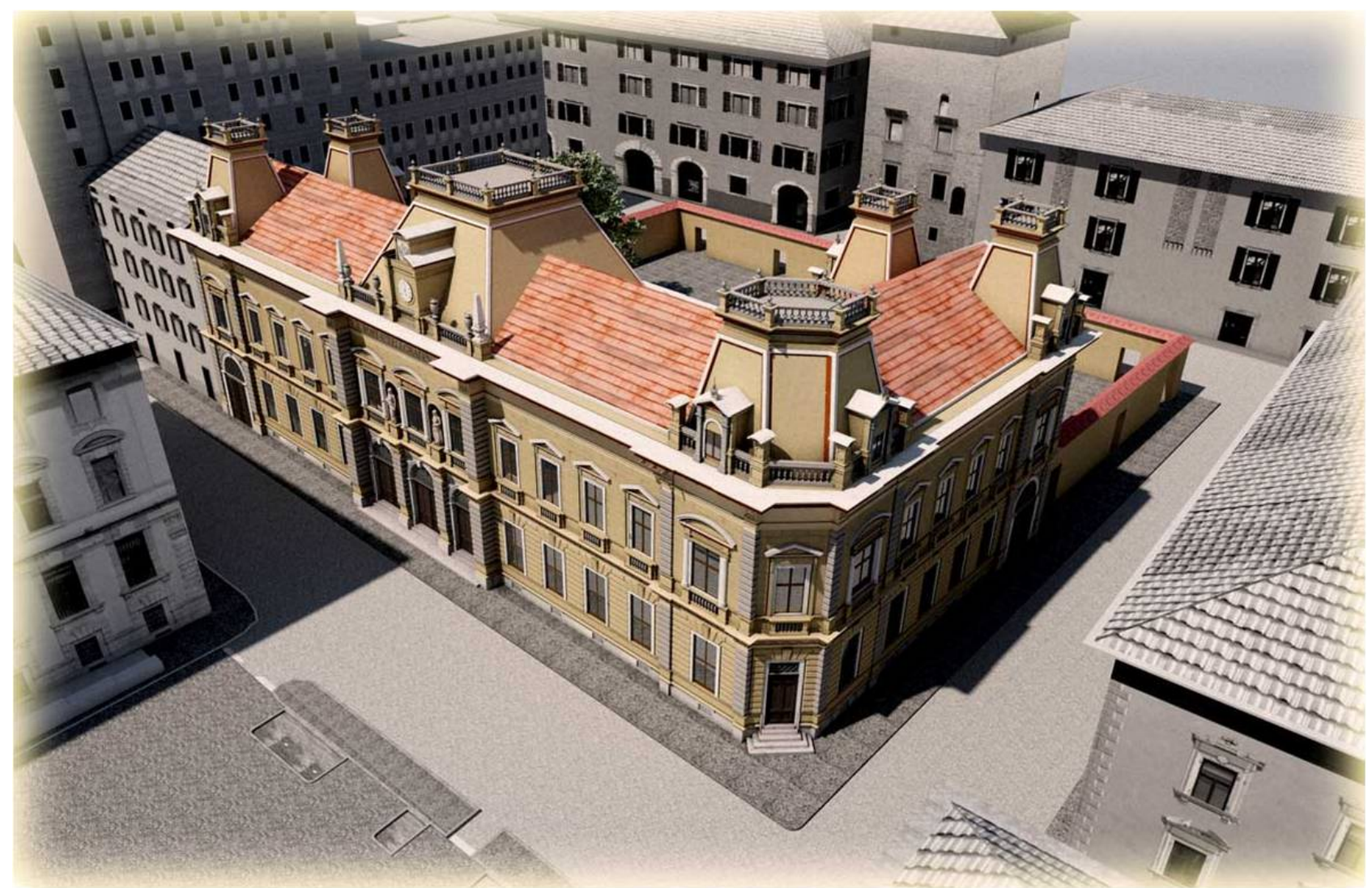

Figure 8. The Post office, Trento: ideal reconstruction of the Hapsburg palace on the basis of archive documents (authors: Ambra Chiariano, Nicola Ianeselli, Stefano Pagani)
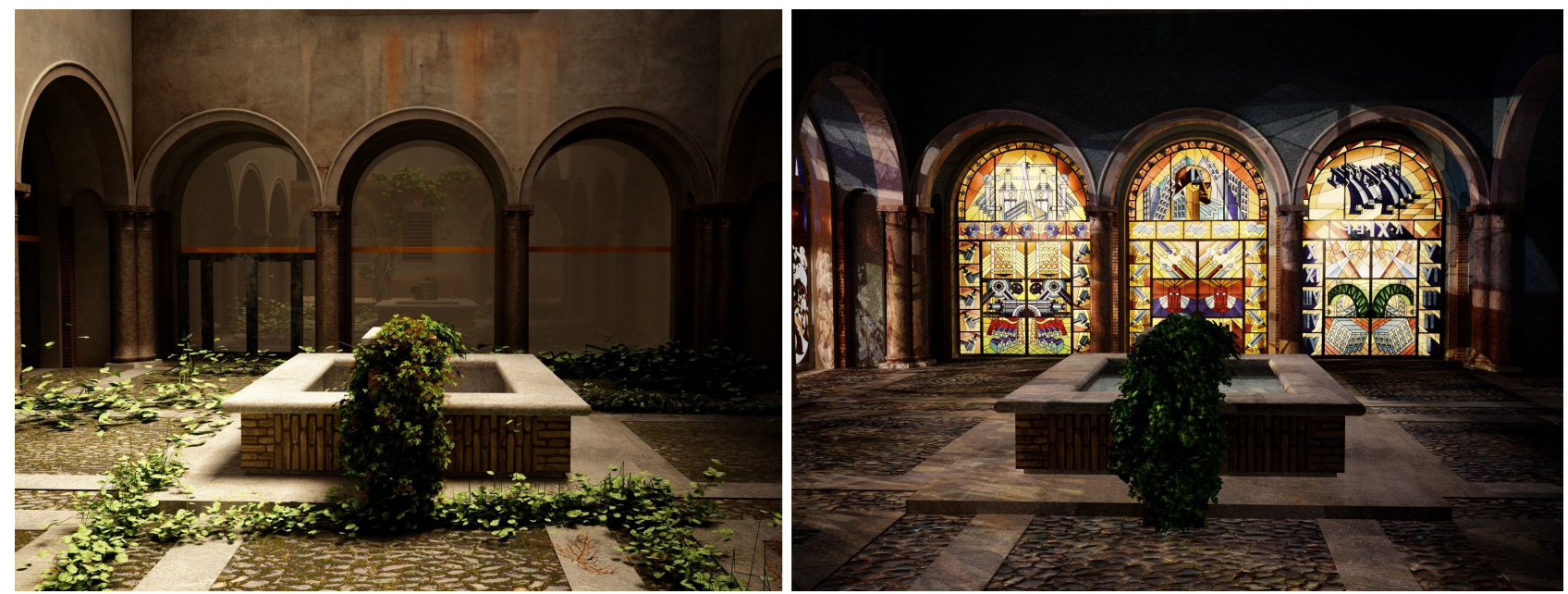

Figure 9. The Post office, Trento: on the left virtual view of the current inner courtyard, on the right ideal reconstruction of the fulllength windows designed by Fortunato Depero (authors: Fabrizio Broch, Irene Cartolari)

The necessity of visualization requires a pre-configuration in the 3D model of one or more virtual scenes, generating by such a figurative 3D model able to express the characters physically perceptible by the object; it consists in defining material properties of surfaces, virtual points of view, the frames on which to make projections, the positions of the lights. Rendering operations and graphic dressing methods culminate in the production of static computer images, known as renderings, and dynamic ones, in which the movement of objects is given by a sequence of images each in slightly different positions: they so become animations, 360 degree panoramas or VRMLs.
The most interesting aspect of these visual simulation processes concerns materials and the use of "textures", each corresponding to the exterior appearance of a surface: except for cases in which the model's complexity requires the use of procedural textures derived from libraries, bitmap textures can describe with great refinement geometrical or colour changes, because produced from images acquired from reality and subjected to bump mapping, an embossing effect that alludes strongly to the tactile sense of matter. In some cases, raster images are also modified with photomontage and photo-editing operations and applications, for example setting a rendered image in a real scene. 

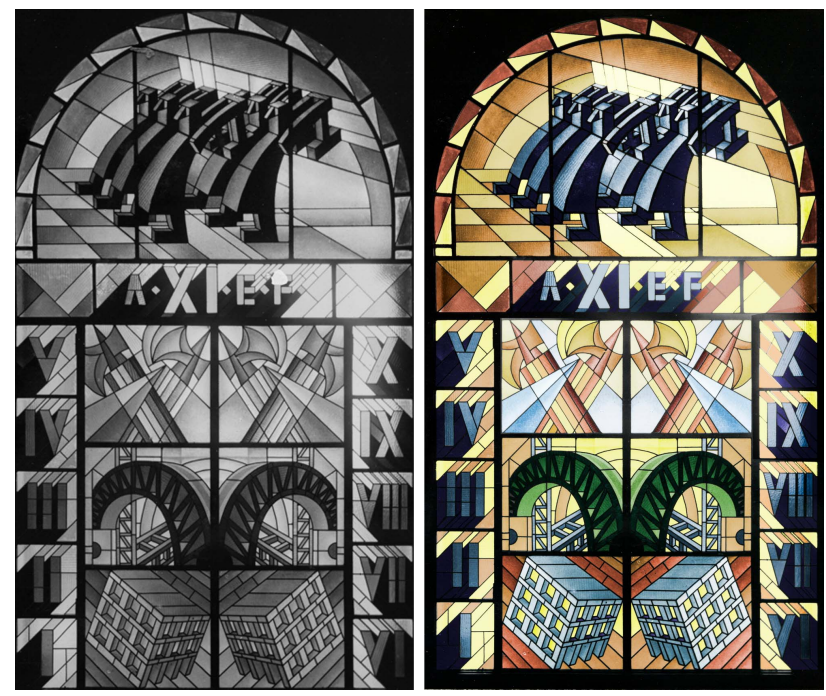

Figure 10. The Post office, Trento: color rendition (recolouring) of stained glass windows designed by Fortunato Depero (authors: Fabrizio Broch, Irene Cartolari)

The extrapolation of geometric information required for traditional project drawings, from the 3D model, follows a completely different route: various tools allow to flatten the model and automatically deduce the section and projection, once determined the reference plans.

Finally hyper-textual communication, projects the figurative model towards a hybridization between different languages and their intellectual content: architecture, music, painting, poetry, combined in a single multimedia presentation that, responds to educational and research purposes, and in addition describes the sensorial stimuli and environmental data, interprets the past and anticipates the future, shows the present under unknown points of view and ensures the remote virtual accessibility of artefacts, cities and landscapes.

\section{CONCLUSIONS}

A cultural project developed within university formation can contribute to the diffusion of a critically conscious use of digital technologies and professional tools; in specialized fields of architectural representation based on computer graphics applications there are two positions of thought that, if applied in daily practice, may establish an immediate proximity between theoretical propositions and its practical usefulness.

The first assumption is about the absolute importance conferred to the consistency of the information contained in representative models, and this belief leads to teach and broadcast the use of software that provide bi-univocal relations of exchange with other systems and mutual recognition of files: This means discouraging the efforts placed in the conversion of data between applications and jointly overcome the so-called "islands of automation", or the communication barriers between users who use different applications characterized by different file formats.

The second decision resides in the heavy demands that freedom must be given to software use, recognizing the value of commercial products at low cost and limited in scope but, more importantly, by extending the interest in the world of open source solutions, completely free software available free on the Internet computer network; information technology is increasingly a primary resource and therefore should be unrestricted and costs-less in the service of any intellectual activity aimed at planning and knowledge achievement: the only investment to provide for is education and learning skills.

\section{REFERENCES}

Caffi, V., 2004. I nuovi metodi per progettare: la rappresentazione e la gestione del progetto di architettura attraverso i software interoperabili. In: EArcom 04. Tecnologie per comunicare l'architettura, Ancona, Italy, pp. 149-155.

Empler, T., 2006. Modellazione 3D \& Rendering. Officina Edizioni, Roma.

Empler, T., 2008. Software libero per la progettazione. DEI, Roma.

Maldonado, T., 2005. Reale e virtuale. Feltrinelli, Milano.

Marcos Alba, C. L., 2010. Forma abierta y diseño parametrizado. Un nuevo modo de proyectar. In: APEGA 2010. New lines of research in Building Engineering, Editorial Marfil, Alcoy, pp. 171-183.

Sacchi, L., Unali, M., 2004. Architettura e cultura digitale. Skira, Milano.

Sanders, K., 1995. The Digital Architect. Wiley, New York.

Steele, J., 2001. Architecture and computers. Action and reaction in the digital design revolution. Laurence King Publishing, London.

\section{ACKNOWLEDGEMENTS}

The authors G. A. Massari (par. 1 and 2), F. Bernardi (par. 3 and 5), A. Cristofolini (par. 4 and 6) would like to thank all the students of the degree course in Engineering / Architecture from the University of Trento, with whom, in these years of working together, have experienced the stages of their journey into the world of digital representation. 